$2014 / 1$

\title{
Stirling Engine with Unidirectional Gas Flow
}

\author{
Ilmars Blumbergs, Institute of Aeronautics, Faculty of Transport and Mechanical Engineering, \\ Riga Technical University
}

\begin{abstract}
In this study, a Stirling engine with unidirectional gas flow configuration of beta type Stirling engine is described and studied from kinematic and thermodynamics points of view. Some aspects of the Stirling engine with unidirectional gas flow engine are compared to classic beta type Stirling engines. The aim of research has been to develop a new type of Stirling engine, using SolidWorks 3D design software and Flow Simulation software. In the development process, special attention has been devoted to heat transfer intensity and the possibility of operating at low temperature difference.
\end{abstract}

Keywords - New design, Stirling engine, unidirectional flow.

\section{INTRODUCTION}

Development of Stirling engines are still in progress worldwide in spite of their admittedly higher cost because of their high efficiency, particularly at part load, their ability to use any source of heat and their non-polluting character.

With a few exceptions of independent individuals, most of the work on Stirling engines has been done by the giant companies of the world. Usually, the vital details of the research are not available.

For many years the Stirling engine has been modified and improved due to its promising theoretical cycle effectiveness. Gas combustion engines are far ahead of Stirling engines because they are inexpensive, but lately, with rising fossil fuel prices, Stirling engines have come back into the picture as a green, inexpensive alternative to the gas combustion engine. As it is known the Carnot cycle is the most efficient of all ideal thermodynamic cycles. Stirling engines can achieve efficiencies of $65 \%$ to $75 \%$ that of the Carnot efficiency [1]; however, efficiency can be easily lost. Since the development of Stirling engine, there have been many interesting and very different configurations of this engine, but there is still room for new inventions. Nowadays, there is renewed interest in Stirling engine development due to its potential in the field of renewable energy. Most of renewable energy investigations now concentrate on solar energy and the investigations have good results. However, the improvement of digital methods for computing the flow process of gasses makes it possible to develop engines that consume different flammable materials with good efficiency. In practice, engine efficiency usually ranges from about $30 \%$ to $40 \%$ within a typical temperature range of $650{ }^{\circ} \mathrm{C}-800{ }^{\circ} \mathrm{C}$, and at an operating speed up to $4000 \mathrm{rpm}$.

Over the years a lot of research around the world has been conducted on regenerators and pistons, but there are still new designs and new conceptual ideas about the engine layout available that are not studied and tested.
Good heat transfer devices and as little dead volume as possible are crucial to achieve any kind of useful power output. In the offered variant of Stirling engine, design cooler volume is separated from other volumes by means of a valve mechanism. Such a solution makes the engine more complex and wastes some energy on valve operation but improves power output by reducing overall dead volume and increasing temperature difference of working fluid.

Typically, the Stirling engines are classified into three groups according to the Kirkley-Walker classification system: Alpha, Beta, and Gamma. Cylinder coupling identifies the way, in which the displacer piston and the power piston are connected and deployed. An Alpha arrangement uses two separate cylinders that each has one sealed piston. Beta group of Stirling engines uses a single cylinder arrangement, where the displacer and power piston are in tandem. A Gamma arrangement is like a hybrid of the Alpha and Beta arrangements [2], [3].

Piston coupling is very important in Stirling engines. There are three basic forms with many further subdivisions. A rigidly coupled Stirling engine uses a solid mechanical linkage that connects the reciprocating elements to each other and the power take-off mechanism. Typical types of rigid coupling include: slider-crank, rhombic drive, swash plate, Scotch Yoke, crank-rocker, and Ross rocker. In gas coupled machines the pistons are coupled by gas dynamic effects rather than solid mechanical linkages. A few examples of this type of coupling are as follows: free-piston, free-displacer, and freecylinder. Liquid coupled Stirling engines use liquid to connect the pistons. There are at least three ways Stirling engines can be liquid coupled: jet-stream, rocking beam, and pressure feedback. The classification of liquid coupling can also be used to describe hybrid Stirling engines that have the power piston rigidly coupled with the output shaft but the displacer gas coupled to the power piston [3] - [7].

The efficiency of Stirling engines is dependent on several different parameters. They can achieve efficiencies of $65 \%$ $70 \%$ of the Carnot efficiency. However, the engine efficiency is reduced up to $0.5 \%$ for each degree rise in coolant temperature.

Dead space in the Stirling engine, which is required to accommodate the necessary heat exchangers, accounts for up to $50 \%$ of the total internal gas volume of the engine. Depending on the location of the dead space, it can have differing effects on the efficiency of the engine. Altering the location can also provide a means to control the power output.

Efficiency is also dependent on the speed at which the engine is running. As the speed increases, aerodynamic drag becomes a predominant factor because it is proportional to the 
square of the speed. To reduce these losses, light working fluids, such as helium and hydrogen, are used. However, these gasses are difficult to contain, especially hydrogen due to its ability to diffuse through solid material. Therefore, Stirling engines that use hydrogen or helium for their working fluid are often expensive and bulky [3], [5-6], [8-11].

\section{ENGINE DESIGN OVERVIEW}

New modification of Beta type Stirling engine with provision of a unidirectional flow of working gas was developed within the EU funded project "Modelling and Research of Effective Small Size Heat Engine Gas Processes", (agreement No.2010/0235/2DP/2.1.1.1.0/10/APIA/VIAA/093, RTU PVS ID 1536). The main idea of the project was to develop a system that could intensively convert heat energy to electrical energy. In the process of system development, special attention was devoted to heat transfer intensity and possibility of work within low temperature difference and little attention - to efficiency. To achieve this goal, Beta type of Stirling engine was chosen as a starting point. Unlike the traditional Beta type Stirling engine, the flow channels were created at the top and at the bottom of the cylinder in order to provide a gas flow from volume between the upper piston (displacer) and the lower piston. Another difference is that working fluid flow channels were created above the upper piston in the cylinder head, leading to the upper part of the cylinder. For the Stirling engine it is important to have as high working gas temperature difference as possible to achieve better efficiency, and in our type of engine it is ensured by organising separate unidirectional flows through the heater and the cooler. Thanks to such a design, the working gas takes heat energy from the walls of channels that are located in the cylinder head, which is heated by an external heat source, while heat energy is diverted to the working gas cooler. Cooler is made with entrance and exit with a mechanism that opens and closes both ends of the cooler. Such a design solution allows us to cut off cooler volume in heating and working phases of the engine. As a result, there is much less dead volume and it is possible to make large coolers without adding dead volume and loosing efficiency and output power.

Dead volume is defined as the total void volume in the Stirling engine. In general, the dead volume is referred to as the volume of working fluid contained in the total dead space in the engine, including the regenerator and transfer port. In normal Stirling engine design practice, the total dead volume is approx. 58\% of the total volume. The dead volume will decrease both the engine network and the thermal efficiency and will increase both the external heat input and output. However, a real engine must have some unavoidable dead volume [5], [6]. In our modification by implementing a valve we can reduce the amount of dead volume by approx. $50 \%$.

In our design, a valve mechanism is added to separate the cooler, and it consumes some power but the overall effect of cutting off large part of dead volume is worth it.
The maximum heat exchange is achieved after the working piston crosses the top dead centre, and that also helps to increase the power output of the engine. It is because an increase in the working gas pressure is achieved, when the crankshaft angle provides more leverage, on which the force created by working gas acts.

\section{DESCRIPTION OF ENGINE AND ITS WORKING PRINCIPLE}

To describe the designed engine, a schematic drawing is presented in Fig. 1. The developed engine consists of the following main parts: a crankshaft, one cylinder, one cylinder head, and connecting rods of crankshaft mechanism, heater, cooler, two pistons, and valve mechanism. The cylinder has two pistons in a reciprocating movement along the cylinder that are mutually offset. Offset is needed to create two variable volumes - the volume between the pistons and the volume between the upper piston and the cylinder head. The upper piston (displacer piston) and the lower piston (power piston) movements in the cylinder are the same as in the classical Beta type Stirling engine (CBTSE) but with a relatively smaller piston offset angle. The designed engine parameters will be described in detail later in this paper [12].

The cooler of designed engine is illustrated schematically in Fig. 1 and shown in blue. Cooler channels (5) start at the bottom of the cylinder (8) and are connected with the top of the cylinder to provide the flow of working gas from space between two pistons (when they are in the lower part of the cylinder) to the top of the cylinder. The direction of working gas flow is from the lower part to the upper part of the cylinder.

The heater of designed engine is shown in red (see Fig. 1). Heater channels (2) start from the cylinder head and end in the upper part of the cylinder but below the lower edge of displacer piston in the upper position so that the volume above the displacer is connected with the volume between pistons through heater channels. The working piston in the upper position is still lower than the exit of heater and cooler channels. The direction of working gas flow in the heater is clockwise in our schematic drawing.

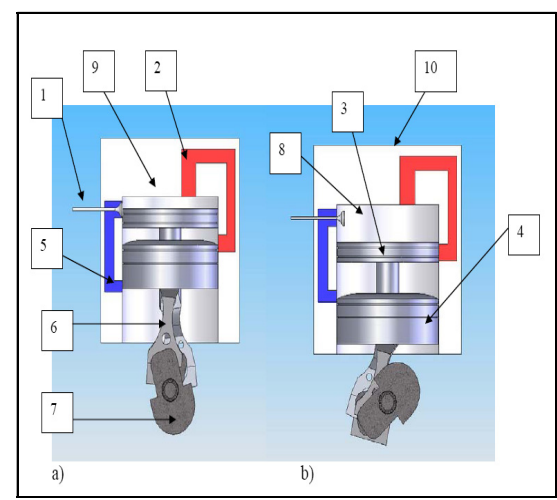

Fig. 1. Schematic illustration of designed engine

Explanation of designations used in Fig. 1: 1 - valve, 2 heater, 3 - upper piston, 4 - lower piston, 5 - cooler, $6-$ 
connecting rods, 7 - crankshaft, 8 - cylinder, 9 - cylinder head, 10 - cylinder block.

The main differences of the presented engine if compared to the classical Beta type Stirling engine, if we look at the engine as such from the point of view of gas thermodynamics, are the following: there is no recuperator in the presented engine, working fluid flows in one direction in engine channels, and the volume of cooler is separated in the power phase. It is selfevident that it is not good to lose recuperator because then we lose some efficiency, but in our project it was more important to increase power output from a constant heat source in the limited space. Due to these differences, the working principle slightly differs from the classical Beta type Stirling engine. We will describe the working principle starting from the power phase that is presented in Fig. 1(a). The crankshaft rotates counter clockwise. The working piston starts to move down, but the displacer continues to move up. By moving upwards, the displacer moves working gas through the channels of heater. The displacer pushes gas through the upper entrance, and because the exit of heater channel is open, the heated gas moves into the section between pistons. As heat energy is added, the working gas pressure increases and gas pushes the working piston down. If compared to CBTSE, the pressure increment is achieved when it is most needed and it occurs when the piston passes the upper dead centre. Intensive heat energy through the heater is added up to 45 degrees after UDC, but the working phase lasts up to 105 degrees from UDC. When the power phase ends, the exit of heater is closed, but the displacer piston body opens the entrance of cooler, which earlier was closed by the working piston body. At the same time, the cooler exit opens. The valve mechanism opens and closes the exit of cooler. The exit of cooler is located in the upper part of the cylinder and this allows the cooled working gas to enter the volume that is located above the displacer. As the crankshaft offset volume between the working piston and displacer decreases, the heated gases that are located between pistons are pushed out into the cooler. At the same time, the volume above the displacer increases and enables the cooled gas to enter. Gas cooling continues up to 80 degrees after BDC. Then valves close the exit of cooler, and the working piston body closes the entrance of cooler. Then the phase of 100 degrees of compression begins.

\section{The Design of Prototype}

The prototype engine was designed by using SolidWorks 2012 CAD software, and some flow simulation was carried out by using SolidWorks Flow Simulation 2012 software package. The designed engine prototype was manufactured and some basic tests were made. The location of temperature and pressure measurement points was selected in such a way that the given parameters could be measured at the inlet of cooler, outlet of cooler and outlet of heater. The designed prototype installed in the test bench is presented in Fig. 2 (without a timing belt, cooler water supply tubes, heat source and test equipment).

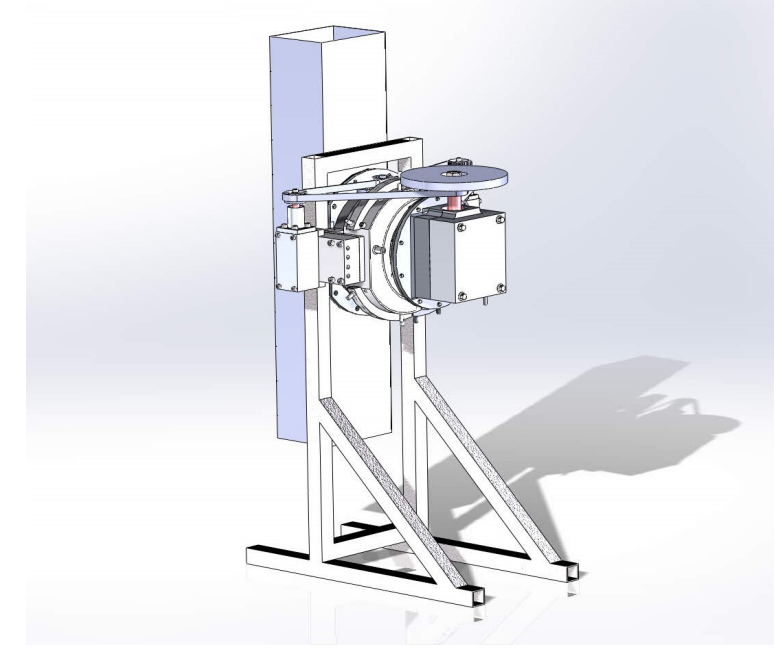

Fig. 2. 3D computer model of designed prototype in the test bench.

Main parameters are provided in Table I. In the design process, a relatively large diameter of piston was taken because the designed engine was oriented to work at medium temperature difference and at relatively low $\mathrm{rpm}$. Such a choice is based on the requirements of intensive heat energy drain in the limited space from heated gas with as little obstruction of the gas flow as possible. These requirements come from the idea to install such devices in the furnace of small houses in the future. In such a solution, heat energy that is taken away from the engine cooler is given to the liquid of furnace liquid circulation system so that no heat from a heat source will be wasted.

TABLE I

MAIN PARAMETERS OF THE DESIGNED PROTOTYPE

\begin{tabular}{|l|l|}
\hline $\begin{array}{l}\text { Working volume (volume of } 1 \\
\text { pulsation) }\end{array}$ & $1100 \mathrm{~cm}^{3}$ \\
\hline Hot end temperature & up to $800^{\circ} \mathrm{C}$ \\
\hline Cold end temperature & up to $60^{\circ} \mathrm{C}$ \\
\hline Initial gas pressure & up to $10 \mathrm{~atm}$ \\
\hline Working gas & air, helium, argon \\
\hline Heat sink in the cooler & with liquid medium \\
\hline Pressure of cooling liquid & up to 3 atm \\
\hline Heat source & gas burner \\
\hline Approximate dimensions & $60 / 50 / 40 \mathrm{~cm}$ \\
\hline $\begin{array}{l}\text { Calculated working gas heat } \\
\text { difference }\end{array}$ & $200{ }^{\circ} \mathrm{C}-400{ }^{\circ} \mathrm{C}$ \\
\hline Valve drive & mechanical \\
\hline Calculated max. RPM & 1500 \\
\hline
\end{tabular}

In Fig. 3, the main three changing volumes of the engine are presented. The total volume that changes because of piston movement varies from about $400 \mathrm{~cm}^{3}$ to $1900 \mathrm{~cm}^{3}$. The total volume, in this case, is a sum of volume between the upper piston and cylinder head and the volume between the upper and lower pistons. Changes in the working volume or the 
volume of one pulsation are depicted by a blue line (a). When the working volume is close to its maximum channels that connect the volume above the upper piston and the volume between the upper and lower pistons, it closes and this enclosed volume is delivered to the cooler. At the same time, when the working volume starts to decrease, the outlet channel of cooler opens and allows the cooled gas to flow into the volume above the upper piston. Thus, this volume is the volume or one portion of total volume that "rotates" in the engine and goes through the cooling and heating phases in every full revolution of crankshaft and that is why it is called the working volume.

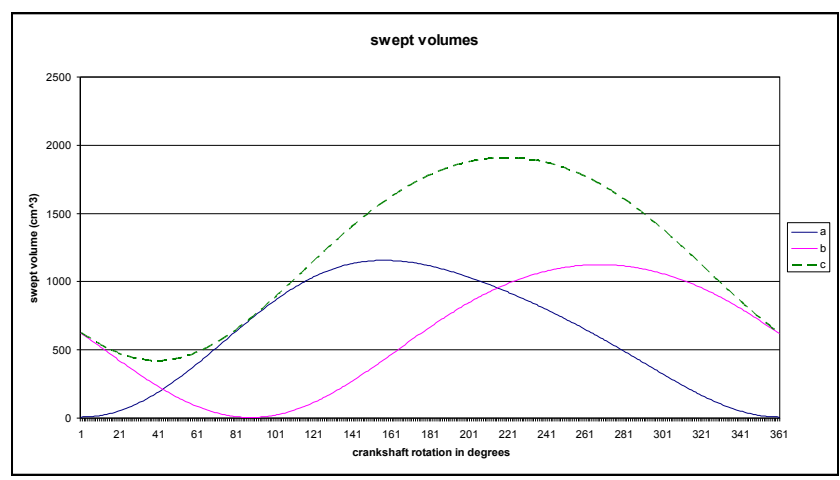

Fig. 3. Swept volumes of designed engine: $a-$ the total changing volume; $b-$ the volume between the upper piston and the cylinder head; $\mathrm{c}-$ the volume between the upper and lower pistons.

In Fig. 3, the crankshaft rotation angle does not start from the upper or lower dead centre of the upper or lower pistons. Zero angle is chosen, when the working volume is at its minimum. Line (b) depicts the volume above the upper piston, and the minimum of this volume means the upper dead centre of upper piston. In this case, useful work is created between 30 and 130 degrees. This is the period of intensive heating of working gas. With such a solution in the designed engine just like in piston engines of internal combustion, heat energy is added only to working fluid at the power stroke. Such a solution allows saving energy by not applying it to working gas on the compression stroke [13], [14].

\section{CONCLUSIONS}

This article presents the design and operating principle of a modified Beta type Stirling engine. The presented invention improves performance of the engine at the same maximum available temperature in the limited space as the existing analogues. The improvement is achieved mainly by reducing the dead volume and by providing a unidirectional flow of working gas. The dead volume can be reduced by approx. $50 \%$ due to provision of a valve mechanism in the engine. Owing to valve implementation, it is possible to achieve different thermodynamic effects that need to be investigated in subsequent projects. At present, the complete computer aided simulation of all thermodynamic processes of gasses in the Stirling engine is hard because even new software products available cannot simulate staged processes with moving boundaries. Therefore, it is very important to make natural experiments, which will reveal the true potential of new modification [15].

\section{ACKNOWLEDGMENTS}

The research project has been funded by the ERAF, and the presented material is part of the project "Modelling and Research of Effective Small Size Heat Engine Gas Processes", agreement No.2010/0235/2DP/2.1.1.1.0/10/ APIA/VIAA/093, RTU PVS ID 1536.

\section{REFERENCES}

[1] J. R. Meijer, “Stirling Engines," In Access Science, September 22, 2010 [Online]. Available http://www.accessscience.com [Accessed Jan. 15, 2014]

[2] J. F. Sandfort, Heat engines. New York: Anchor Books Doubleday \& Company, 1962.

[3] G. Walker, Stirling engines. Oxford: Clarendon Press, 1980.

[4] C. Hooper and G. T. Reader, Stirling engines. Cambridge: Cambridge University Press, 1983.

[5] W. R. Martini, "Stirling engine design manual," April 1978. [Online]. Available: http://ntrs.nasa.gov [Accessed: Jan. 21, 2014].

[6] S. W. Kongtragool, Thermodynamic analysis of a Stirling engine including dead volumes of hot space, cold space and regenerator. Elsevier Ltd., 2005.

[7] R. Wiliam, Stirling Engine Design Manual. Martini Engineering, 1983.

[8] W. B. Stine, "Stirling engines," in The CRC handbook of mechanical engineers. CRC Press, 1998, pp. 67-76.

[9] R. Wiliam, Stirling Engine Design Manual. Martini Engineering, 1983.

[10] P. Noel, Nightingale Automotive Stirling Engine. Mod II Design Report. NASA CR-175106. New York: Mechanical Technology Inc., 1986.

[11] E. D. William and S. K. Richard, "Automotive Stirling Engine Development Project," February 1997. [Online]. Available: http://ntrs.nasa.gov [Accessed: Jan. 21, 2014].

[12] I.Blumbergs, V.Ušakovs, N.Sidenko and D.Jel̦isejevs "One-way Flow Beta-type Stirling Engine,” LV Patent: LV Nr.14483, April 20, 2012.

[13] I. Blumbergs and V. Ushakov, "Specifics of Stirling Engine with Recuperation Heat Exchanger," Machines, Technologies, Materials, vol.6, pp. 17-19, 2012.

[14] V. Ushakov and I. Blumbergs, The Computer Analysis of the Heat Exchanger of Drive Stirling with the Nonsteady Pulsing Stream of the Heat Transfer Medium: The 20th International Scientific and Technical Conference on Transport, Road-Building, Agricultural, Hoisting \& Hauling and Military Technics and Technologies, pp. 27-29, June 27-29, Varna, Bulgaria.

[15] D. Thimsen, Stirling Engine Assessment. EPRI, Palo Alto, 2002.

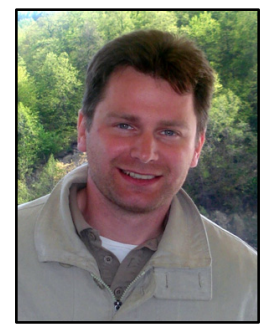

Ilmars Blumbergs. In 2012, he received a Doctoral Degree in Engineering Science from the Aviation Institute of RTU. In 2005, he received a Master's Degree in Aviation Transport from the Aviation Institute of RTU. In 2001, he graduated from the Aviation Institute of RTU and obtained a Bachelor's Degree in Automotive Engineering.

Work experience: in the period of 2001-2003 Engineer-constructor at Partneris L.V. 1td. (designing and manufacturing of equipment for polymer concrete products); in the period of 2006-

2012 Deputy Head of the Aviation Institute; since 2005 academic staff member; at present, Owner and Chief Designer of IBTEH prototype design company, Riga, Latvia.

Mobile phone: +3712959669

E-mail: ilmars-b@inbox.lv 